\title{
Population structure of the fish pathogen Flavobacterium psychrophilum at whole-country and model river levels in Japan
}

Erina Fujiwara-Nagata ${ }^{12^{*}}$, Céline Chantry-Darmonn ${ }^{2,3}$, Jean-François Bernardet ${ }^{2}$, Mitsuru Eguchi ${ }^{1}$, Eric Duchaud ${ }^{2+}$ and Pierre Nicolas ${ }^{3+}$

\begin{abstract}
The bacterium Flavobacterium psychrophilum is a serious problem for salmonid farming worldwide. This study investigates by multilocus sequence typing (MLST) the population structure of this pathogen in Japan where it is also a major concern for ayu, a popular game fish related to salmoniforms. A total of 34 isolates collected across the country and 80 isolates sampled in a single model river by electrofishing were genotyped. The data accounting for 15 fish species allowed identifying 35 distinct sequence types (ST) in Japan. These ST are distinct from those reported elsewhere, except for some ST found in rainbow trout and coho salmon, two fish that have been the subject of intensive international trade. The pattern of polymorphism is, however, strikingly similar across geographical scales (model river, Japan, world) in terms of the fraction of molecular variance linked to the fish host $(\sim 50 \%)$ and of pairwise nucleotide diversity between ST $\left(\sim 5 \mathrm{Kbp}^{-1}\right)$. These observations go against the hypothesis of a recent introduction of $F$. psychrophilum in Japan. Two findings were made that are important for disease control: 1) at least two independent F. psychrophilum lineages infect ayu and 2) co-infections of the same individual fish by different strains occur.
\end{abstract}

\section{Introduction}

Diseases are an important problem in fish farming and control of bacterial pathogens relies mostly on repeated antibiotic treatments incompatible with the development of sustainable aquaculture [1]. The fish-pathogenic bacterium Flavobacterium psychrophilum is the causative agent of the "bacterial cold water disease" (BCWD) and the "rainbow trout fry syndrome", two salmonid diseases that cause considerable losses in rainbow trout (Oncorhynchus mykiss) and coho salmon (Oncorhynchus kisutch) farming industries worldwide [2-5]. In Japan, Flavobacterium psychrophilum was first isolated in 1987 from cultured ayu (Plecoglossus altivelis altivelis), a fish related to salmoniforms [6]. The status of F. psychrophilum in the country before the development of the fish farming industry and possible importation from foreign sources is unclear [7-9] but it is currently recognized as a serious

\footnotetext{
* Correspondence: erina_nagata@nara.kindai.ac.jp

${ }^{\dagger}$ Equal contributors

'Department of Fisheries, Kinki University, Nara, Japan

2INRA, Virologie et Immunologie Moléculaires UR892, Jouy-en-Josas, France Full list of author information is available at the end of the article
}

problem, in particular for ayu [10]. Indeed, to increase the stocks of this very popular game fish, juveniles hatched from artificially fertilized eggs or captured in coastal areas are released into rivers by fish farming companies and experimental stations located in each prefecture. The bacterium is then probably disseminated with ayu juveniles. Infections are now repeatedly reported not only in fish farms but also in natural environments $[6,11]$.

Many species beyond the ayu and farmed rainbow trout and coho salmon have been reported to harbor F. psychrophilum in Japan. These include migrating salmonids whose geographical ranges extend throughout the north-Pacific and more local species and subspecies. The actual host range of $F$. psychrophilum is, however, not limited to salmonids [12], although the infection is apparently less severe in non-salmonids [13]. In Japan, F. psychrophilum has been reported on a number of local non-salmonid wild fish species [14-16].

Understanding the degree and determinants of host specificity of $F$. psychrophilum strains as well as their routes of dissemination would help setting rational

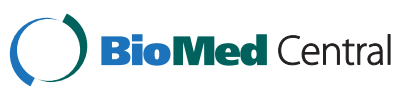


practices to limit the spreading of the disease. Correlations between bacterial genotype and host fish have been observed in several studies on field isolates [14,17-20] and we recently reported that ayu could be experimentally infected in bath infection challenges by isolates collected from ayu but not from coho salmon or rainbow trout [14]. However mimicking the conditions of natural infections is generally difficult for $F$. psychrophilum [21-24] and field studies that would provide a deeper knowledge of the distribution of the genotypes in terms of geographical area and host fish species are essential.

Following the publication of the complete genome sequence of a F. psychrophilum strain [25], a first Multilocus sequence typing (MLST) analysis was conducted on a set of 50 isolates collected from 11 different fish species in 12 different countries over the world [17]. This initial study identified 33 different sequence types (ST), some of which could be grouped into clonal complexes (CC) associated with particular fish species, especially rainbow trout and coho salmon. The results also revealed remarkably high rates of homologous recombination and limited nucleotide diversity. However, the small number of isolates from each particular geographical origin did not allow the description of population structure at a regional scale. A more recent analysis of 66 additional isolates from farmed rainbow trout in France [26] concluded to the predominance of a single clonal complex. In the present study we investigated the genetic diversity of $F$. psychrophilum in Japan using a higher number of isolates than for any other region and taking into account the diversity of fish hosts. We also compare the patterns of polymorphism at the world, country and single model river levels.

\section{Materials and methods}

\section{Field sampling of $F$. psychrophilum isolates}

A first set of Japanese F. psychrophilum isolates was contributed by correspondents all over Japan (listed in Additional file 1). A second set of isolates was collected in the downstream area of the $\sim 9.5 \mathrm{~km}$ long Chinai River near $(\sim 0.3 \mathrm{~km})$ its mouth into Lake Biwa, the largest lake in Japan. With an authorization of the Shiga prefecture, fish were caught by electrofishing, kept at low temperature into tanks, quickly transported to our laboratory and euthanized by severing their spinal cord. Gill samples were cut into pieces of $\sim 25 \mathrm{~mm}^{2}$ and suspended in $1 \mathrm{~mL}$ of phosphate buffered saline (PBS). The tubes were vortexed during $30 \mathrm{~s}$ at maximum speed and the suspensions were further diluted in PBS as to obtain well-separated colonies on modified cytophaga (MCYT) agar [27]. Samples from internal organs and skin lesions were collected using a sterile loop and streaked directly onto MCYT plates. Water samples (containing $2000 \sim 3000 \mathrm{cfu} \mathrm{mL}^{-1}$ ) were diluted to $10^{-4}$ in PBS prior to being spread onto MCYT plates. Caddisfly cases were vigorously vortexed in $1.5 \mathrm{~mL}$ of PBS and the suspensions were diluted and spread onto MCYT plates. All plates were incubated at $15^{\circ} \mathrm{C}$ for 4 days. Yellow colonies were selected for identification as $F$. psychrophilum based on the PCR amplification of the $16 \mathrm{~S}$ rRNA and $g y r B$ genes $[18,28,29]$ according to the guidelines of the council for the control of bacterial cold water disease of ayu (Japanese Ministry of Agriculture, Forestry and Fisheries). Each isolate received a unique identifier containing the date of sampling encoded in the "yymmdd" format.

\section{Multi locus sequence typing}

The seven target loci as well as the PCR and sequencing protocols are listed in Additional file 2. The sequences were assembled using Phred/Phrap/Consed [30], verified manually to ensure high quality, and deposited in Genbank (GenBank:KC203886-KC204683). In keeping with MLST standards [31,32], arbitrary numbers served for unambiguous identification of the AT (particular alleles at particular loci) and ST (unique combinations of AT at the seven loci). To facilitate large scale studies the following changes were made compared to the initial study [17]: PCR amplification was performed with an optimized touchdown protocol; 5' extensions were added to the PCR primers to allow sequencing of the 7 loci with the same pair of primers; and AT attribution was based on slightly shortened sequences. The data, including the genotypes from $[17,26]$, are made available in a new version of the $F$. psychrophilum MLST database [33] which uses the BIGSdb system [34].

A tree depicting AT-sharing between ST was built by hierarchical clustering with R; the function "hclust" using the single link aggregation method and drawn with the R package "ape". The eBURSTv3 software with default settings [35] was used to obtain a "population snapshot" highlighting the relationships between closely related ST. Clonal complexes (CC) were defined using the criterion of single locus variant (SLV) connections between ST. Analyses of nucleotide diversity, including analysis of molecular variance [36], were coded in R. Nucleotide diversity was computed on pairwise comparisons between unique ST rather than between isolates to minimize the impact of sampling biases; as a consequence, the values were slightly higher than those initially reported in Nicolas et al. [17].

\section{Results and discussion}

Sampling of $F$. psychrophilum diversity at whole-country and model river levels

We analyzed bacterial isolates representative of two different geographical levels. In addition to 6 MLST 
profiles already available [17], we genotyped a first set of 34 F. psychrophilum isolates collected between 1993 and 2005 from a variety of locations all over Japan to account for the diversity at the country level. Our second set consisted of 80 isolates obtained for this study between August 2005 and December 2006 from a single model river in which fish were captured irrespective of their disease status to minimize sampling biases. This strategy allowed retrieving isolates from 6 fish species, as well as 4 isolates from water samples and 1 from the case of a caddisfly (order Trichoptera). This raises the number of MLST profiles available to study the F. psychrophilum population structure in Japan to 120 and the number of sampled host fish species to 15 . Table 1 provides a detailed summary of the data. These could be compared to 110 other MLST profiles from the rest of the world $[17,26]$.

\section{Population structure at the country level}

Our MLST data reveal a high genetic diversity of F. psychrophilum in Japan. The total number of different ST in the Japanese isolate collection amounts to 35, among which 32 are only reported in Japan (Figure 1). At the nucleotide level, these 35 ST harbor a pairwise nucleotide diversity of $5.4 \mathrm{Kbp}^{-1}$ comparable to the 5.6 $\mathrm{Kbp}^{-1}$ found in the 230 isolates representative of worldwide diversity. This indicates that the structure of the F. psychrophilum population is at most only marginally linked to geographical origin. Indeed, in our data, as much as $88 \%$ of the nucleotide sites that are polymorphic in Europe are also polymorphic in Japan.

Many of the ST that were sampled several times are associated with the defined host fish (Figures 1 and 2). The ST of most Japanese isolates (76\%) could indeed be classified into six CC and the ST from a same CC also tended to infect similar host fish. Each $\mathrm{CC}$ is named after a representative ST. These six $\mathrm{CC}$ are the following: CC-ST52 (59 isolates) from ayu; CC-ST48 (13 isolates) from ayu; CC-ST56 (12 isolates) from ayu and cyprinids; CC-ST2 (3 isolates) from rainbow trout; CC-ST9 (2 isolates) from coho salmon; and CC-ST54 (2 isolates) from masou salmon. Of note, CC-ST48 and CC-ST56 that both infect ayu are connected by a double locus variant (DLV) link and therefore probably share a recent common ancestor, even though here they are distinguished using the stringent operational definition of $\mathrm{CC}$ based on the SLV links.

Analysis of the molecular variance confirmed that the association between genotype and the host fish in Japan was highly statistically significant and showed that it explains as much as $44.2 \%$ of the genetic variance. This level was slightly lower but close to the $51.3 \%$ reported at the worldwide level by Nicolas et al.
[17] and to the $48.3 \%$ computed here on the new set of 230 isolates.

At least two separate lineages (CC-ST52 and CC-ST48/ CC-ST56) infect this fish species, a fact that is important for the future treatment and prevention of BCWD in ayu. Strains in these three CC showed various levels of virulence against ayu in bath infection challenges and strains from CC-ST48/CC-ST56 generally seem more virulent than those from CC-ST52 [14]. Of note, CC-ST56 also infects cyprinids in Japan and [14] reported that ST-51 isolates from cyprinids cause mortality in ayu by bath infection challenge, providing experimental support for the possibility of transfer between carp and ayu in CC-ST56.

\section{Footprints and possible mechanisms of transcontinental dissemination}

The absence of clear genetic signal reflecting the geography indicates mixing between $F$. psychrophilum populations located on different continents. Such a deep effect on the whole population probably involved recurrent natural dissemination before the development of commercial exchanges. This may seem surprising for a fish-pathogenic bacterium found in freshwater that one can believe limited by watersheds. However, long-distance dissemination events do not need to be frequent to have a substantial impact on genetic structure: a few migrants per generation in the entire population have dramatic homogenizing consequences in idealized models [37,38]. Potential mechanisms include fish and bird migrations but airborne dissemination may be another possibility. Indeed, $F$. psychrophilum is able to survive in pure water [39] and freshwater bacteria -including Flavobacteriaceae- were recently sampled in the upper troposphere [40]. Alternatively, genetic mixing can involve a succession of more frequent small-distance steps. The DLV link between ST44 sampled in Japan from H. nipponensis and ST104 sampled in France from rainbow trout might be a footprint of natural dissemination. Both ST have been sampled only once and are not connected to other genotypes, which suggests that the ST44/ST104 lineage infects farmed fish only sporadically and should thus not be prone to dissemination by human activities.

In sharp contrast, the three ST also reported in other countries (ST9, ST10 and ST13) are associated to rainbow trout and coho salmon. These are two fish species with wide geographical distribution and whose eggs and broodfish have been imported to Japan (vertical transmission from parent to offspring via eggs is highly suspected [41]). Two other ST that we found in Japan are connected by SLV links to ST found abroad: ST17, sampled twice from rainbow trout, is linked to the main rainbow trout clonal complex (CC-ST2); and CC-ST56, infecting ayu and cyprinids in Japan, is linked to ST14 
Table 1 MLST profiles and background information for the $120 \mathrm{~F}$. psychrophilum isolates from Japan

\begin{tabular}{|c|c|c|c|c|c|c|}
\hline Isolate $^{a}$ & $\mathrm{ATs}^{\mathrm{b}}$ & $\mathrm{ST}^{\mathrm{c}}$ & Prefecture $^{d}$ & Host $^{\mathrm{e}}$ & Tissue & Year \\
\hline FPC 837* & $5,4,4,4,2,4,4$ & ST5 & Tokushima & P. altivelis (ayu) & Kidney & 1987 \\
\hline FPC $840^{*}$ & $5,4,4,4,2,4,4$ & ST5 & Tokushima & & Kidney & 1987 \\
\hline PH9351 & $19,24,19,5,8,1,8$ & ST45 & Hiroshima & & Ovary & 1993 \\
\hline CS-1 & $19,24,19,5,8,1,8$ & ST45 & Gifu & & Kidney & 1995 \\
\hline $96-4$ & $5,24,4,4,2,4,4$ & ST52 & Gifu & & Kidney & 1996 \\
\hline PH-0003 & $19,24,19,5,8,1,8$ & ST45 & Hiroshima & & Kidney & 2000 \\
\hline SG011227 & $5,24,2,6,8,1,8$ & ST56 & Shiga & & Kidney & 2001 \\
\hline PH-0209 & $19,24,19,6,8,1,8$ & ST48 & Hiroshima & & Kidney & 2002 \\
\hline AK-0527 & $19,19,19,2,13,29,28$ & ST53 & Kyoto & & Lower jaw & 2005 \\
\hline AK-0536 & $19,19,19,2,13,29,28$ & ST53 & Kyoto & & Lower jaw & 2005 \\
\hline AK-0531 & $19,19,19,2,13,29,28$ & ST53 & Kyoto & & Kidney & 2005 \\
\hline AK-05137 & $19,19,19,2,13,29,28$ & ST53 & Kyoto & & Skin lesion & 2005 \\
\hline KU050822-1 & $5,24,4,4,2,4,4$ & ST52 & Shiga (MR) & & Skin lesion & 2005 \\
\hline KU050822-3 4 & $5,24,4,4,2,4,4$ & ST52(2) & Shiga (MR) & & Skin lesion & 2005 \\
\hline KU051024-5 & $5,24,4,4,2,4,4$ & ST52 & Shiga (MR) & & Gill & 2005 \\
\hline KU051024-6 & $5,24,4,4,2,4,4$ & ST52 & Shiga (MR) & & Coelomic fluid & 2005 \\
\hline KU051024-7 & $5,24,4,4,2,4,4$ & ST52 & Shiga (MR) & & Coelomic fluid & 2005 \\
\hline KU051024-8 11 & $5,24,2,6,10,1,8$ & ST65(4) & Shiga (MR) & & Egg & 2005 \\
\hline KU051024-12 13 & $5,24,4,4,2,4,4$ & ST52(2) & Shiga (MR) & & Egg & 2005 \\
\hline KU051024-14 17 & $5,24,4,4,2,4,4$ & ST52(4) & Shiga (MR) & & Egg & 2005 \\
\hline KU060427-1 & $5,24,4,4,2,4,4$ & ST52 & Shiga (MR) & & Gill & 2006 \\
\hline \multirow[t]{2}{*}{ KU060626-1 3} & $19,24,19,6,8,1,8$ & ST48(1) & Shiga (MR) & & Kidney & 2006 \\
\hline & $5,24,4,4,2,4,4$ & ST52(2) & - & & - & - \\
\hline KU060626-4 6 & $5,24,2,6,8,1,27$ & ST49(3) & Shiga (MR) & & Kidney & 2006 \\
\hline KU060626-7 9 & $5,24,4,4,2,4,4$ & ST52(3) & Shiga (MR) & & Kidney & 2006 \\
\hline KU060626-10 12 & $5,24,4,4,2,4,4$ & ST52(3) & Shiga (MR) & & Kidney & 2006 \\
\hline KU060626-13 15 & $5,24,4,4,2,4,4$ & ST52(3) & Shiga (MR) & & Kidney & 2006 \\
\hline KU060626-16 18 & $5,24,4,4,2,4,4$ & ST52(3) & Shiga (MR) & & Kidney & 2006 \\
\hline \multirow[t]{2}{*}{ KU060626-19 21} & $19,24,19,6,8,1,8$ & ST48(2) & Shiga (MR) & & Kidney & 2006 \\
\hline & $5,24,2,5,8,1,35$ & ST67(1) & - & & - & - \\
\hline KU060626-22 24 & $5,24,4,4,2,4,4$ & ST52(3) & Shiga (MR) & & Kidney & 2006 \\
\hline KU060626-25 27 & $5,24,4,4,2,4,4$ & ST52(3) & Shiga (MR) & & Kidney & 2006 \\
\hline \multirow[t]{2}{*}{ KU060626-28 36} & $19,24,19,6,8,1,8$ & ST48(1) & Shiga (MR) & & Kidney & 2006 \\
\hline & $5,24,4,4,2,4,4$ & ST52(7) & - & & - & - \\
\hline KU060626-37 39 & $19,24,19,6,8,1,8$ & ST48(3) & Shiga (MR) & & Kidney & 2006 \\
\hline KU060626-40 42 & $5,24,4,4,2,4,4$ & ST52(3) & Shiga (MR) & & Kidney & 2006 \\
\hline \multirow[t]{2}{*}{ KU060626-43 46} & $19,24,19,6,8,1,8$ & ST48(1) & Shiga (MR) & & Kidney & 2006 \\
\hline & $5,24,4,4,2,4,4$ & ST52(3) & - & & - & - \\
\hline KU060626-57 & $5,24,4,4,2,4,4$ & ST52 & Shiga (MR) & & Skin lesion & 2006 \\
\hline KU060626-59 & $19,24,19,6,8,1,8$ & ST48 & Shiga (MR) & & Skin lesion & 2006 \\
\hline KU060920-5 6 & $5,24,4,4,2,4,4$ & ST52(2) & Shiga (MR) & & Gill & 2006 \\
\hline KU060920-7 8 & $5,24,4,4,2,4,4$ & ST52(2) & Shiga (MR) & & Gill & 2006 \\
\hline KU060920-19 & $5,24,4,4,2,4,4$ & ST52 & Shiga (MR) & & Milt & 2006 \\
\hline
\end{tabular}


Table 1 MLST profiles and background information for the 120 F. psychrophilum isolates from Japan (Continued)

\begin{tabular}{|c|c|c|c|c|c|c|}
\hline $\mathrm{OH}-0224$ & $2,30,20,2,22,22,23$ & ST54 & Hiroshima & O. masou subsp. & Gill & 2003 \\
\hline $96-1$ & $17,26,18,9,19,24,24$ & ST43 & Gifu & $\begin{array}{c}\text { (resp. yamame, amago x2, } \\
\text { and biwamasu) }\end{array}$ & Kidney & 1996 \\
\hline $\mathrm{OH}-0519$ & $2,30,20,2,23,22,23$ & ST55 & Hiroshima & & Kidney & 2005 \\
\hline SG030207 & $15,24,10,3,2,12,11$ & ST40 & Shiga & & Kidney & 2003 \\
\hline FPC 813* & $2,8,2,2,2,10,2$ & ST17 & Tokyo & O. mykiss (rainbow trout) & Kidney & 1992 \\
\hline FPC $814^{*}$ & $2,8,2,2,2,10,2$ & ST17 & Tokyo & & Kidney & 1992 \\
\hline CS-3 & $14,23,4,10,6,22,2$ & ST39 & Gifu & & Kidney & 1995 \\
\hline SG950607 & $2,8,2,2,2,2,2$ & ST10 & Shiga & & Kidney & 1995 \\
\hline SG010808 & $2,29,15,12,17,27,26$ & ST47 & Shiga & & Kidney & 2001 \\
\hline $\mathrm{OH}-0203$ & $2,8,2,2,2,2,2$ & ST10 & Hiroshima & & Kidney & 2002 \\
\hline 0312 & $7,28,4,5,21,28,21$ & ST50 & Yamanashi & & Kidney & 2003 \\
\hline$y-2$ & $2,8,2,2,2,2,2$ & ST10 & Iwate & & Kidney & 2005 \\
\hline$y-3$ & $4,25,4,5,18,23,23$ & ST42 & Iwate & & Kidney & 2005 \\
\hline FPC $830^{*}$ & $4,7,6,5,6,8,4$ & ST13 & Miyagi & O. kisutch (coho salmon) & Kidney & 1990 \\
\hline FPC $831^{*}$ & $11,18,7,5,14,18,17$ & ST30 & Iwate & & Peduncle & 1990 \\
\hline FPM960724 & $11,18,7,5,14,18,17$ & ST30 & Miyagi & & not available & 1996 \\
\hline FPM960726 & $4,7,6,5,6,5,4$ & ST9 & Miyagi & & Kidney & 1996 \\
\hline$x-2$ & $11,18,7,5,14,18,17$ & ST30 & Iwate & & Kidney & 2005 \\
\hline SG020617 & $16,4,17,5,10,12,22$ & ST41 & Shiga & S. leuc. (iwana) & Kidney & 2002 \\
\hline SG980216 & $18,27,10,7,20,25,25$ & ST44 & Shiga & H. nipponensis (wakasagi) & Egg & 1998 \\
\hline SG010619 & $5,24,4,4,2,4,4$ & ST52 & Shiga & & Kidney & 2001 \\
\hline SG040302 & $20,31,19,2,23,30,28$ & ST57 & Shiga & & Kidney & 2004 \\
\hline GM2127 & $4,28,8,11,1,26,4$ & ST46 & Gunma & T. hakonensis (ugui) & Skin lesion & 1999 \\
\hline $\mathrm{CH}-9401$ & $5,24,8,6,8,1,8$ & ST51 & Hiroshima & C. carpio (koi) & Skin lesion & 1994 \\
\hline KU061226-2 3 & $24,21,15,1,8,34,33$ & ST63(2) & Shiga (MR) & Cyprinid fish & Gill & 2006 \\
\hline $\mathrm{CH}-0411$ & $5,24,8,6,8,1,8$ & ST51 & Hiroshima & C. carassius (funa) & Kidney & 2004 \\
\hline KU061226-1 & $25,35,10,2,16,1,4$ & ST64 & Shiga (MR) & P. jouyi (takahaya) & Gill & 2006 \\
\hline PH-9348 & $21,32,10,7,24,31,29$ & ST58 & Hiroshima & Z. platypus (oikawa) & Kidney & 1993 \\
\hline ZH-0001 & $5,24,8,6,8,1,8$ & ST51 & Hiroshima & & Kidney & 2000 \\
\hline KU051024-4 & $5,24,4,4,2,4,4$ & ST52 & Shiga (MR) & T. bre. (numachichibu) & Gill & 2005 \\
\hline KU051128-1 & $1,15,16,5,19,35,34$ & ST66 & Shiga (MR) & Gymnogobius sp. & Gill & 2005 \\
\hline KU051128-4 & $23,29,11,13,13,5,1$ & ST60 & Shiga (MR) & L. rei. (sunayatsume) & Gill & 2005 \\
\hline KU051128-8 & $23,29,11,13,13,5,1$ & ST60 & Shiga (MR) & River water & not applicable & 2005 \\
\hline KU051128-10 & $22,31,4,10,19,32,3$ & ST59 & Shiga (MR) & & not applicable & 2005 \\
\hline KU060920-2 & $5,24,4,4,2,4,4$ & ST52 & Shiga (MR) & & not applicable & 2006 \\
\hline KU060920-4 & $5,24,4,4,2,4,4$ & ST52 & Shiga & & not applicable & 2006 \\
\hline KU061128-1 & $5,34,8,1,26,26,32$ & ST62 & Shiga (MR) & & not applicable & 2006 \\
\hline KU051128-6 & $8,33,8,1,25,33,31$ & ST61 & Shiga (MR) & Case of caddisfly & not applicable & 2005 \\
\hline
\end{tabular}

${ }^{a}$ Isolate identifier. Isolates are ordered by host fish species and then by sampling year; ${ }^{*}$ indicates isolates already included in Nicolas et al. [17]. When several isolates have been collected from the same individual fish their identifiers are reported in a condensed format (i.e. KU060626-40 42 stands for KU060626-40, KU060626-41 and KU060626-42).

${ }^{b}$ Allele types (AT) for the seven loci ordered trpB, gyrB, dnaK, fumC, murG, tuf and atpA.

' Sequence type (ST). When several isolates were collected from the same individual fish the number in parentheses indicates the frequency of each ST. If different ST were found in the same fish, each ST is reported on a separate line but information on prefecture, tissue and year are not repeated (replaced by -). ${ }^{d}$ Geographical origin of the isolate in Japan. (MR) indicates an isolate from the model river in the Shiga prefecture.

e The host fish species or environmental sample source. The common name used in Japan is given in parentheses. Genus and sometimes species names have been abbreviated in this column. Full species names: Plecoglossus altivelis, Oncorhynchus masou, Oncorhynchus mykiss, Oncorhynchus kisutch, Salvelinus leucomaenis, Hypomesus nipponensis, Trybolodon hakonensis, Cyprinus carpio, Carassius carassius, Phoxinus jouyi, Zacco platypus, Tridentiger brevispinis, and Lethenteron reissneri. 


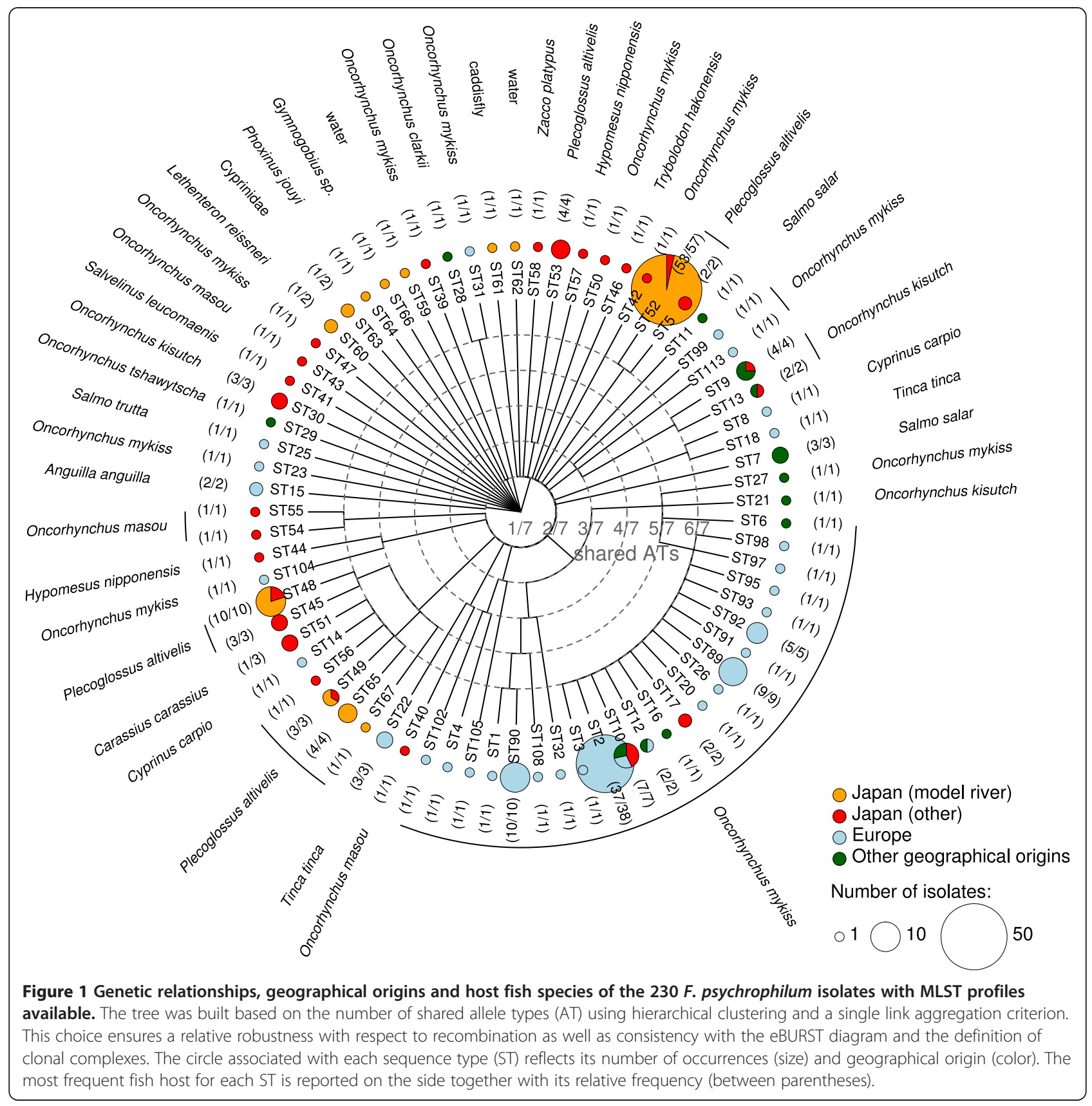

sampled from a carp in Germany. In both cases, commercial exchanges may be invoked to explain these SLV links between Japanese and European isolates. Namely, carps have been traded between Japan and Europe, and rainbow trout have been imported from North America to both Japan and Europe. Of note, the diversity of CC-ST48/CC-ST56 found in Japan is a strong indication that dissemination of this lineage occurred from Japan to Europe rather than the contrary; altogether we found no indication suggesting that strains infecting ayu might have been recently imported from foreign sources.

\section{Population structure in the model river}

Extensive sampling of a model river unveils an unanticipated level of diversity in a restricted geographical area. We found 12 different ST in the model river and a general pattern of polymorphism surprisingly similar to that of the whole country and worldwide levels. Namely, the average pairwise nucleotide difference between the ST was $4.8 \mathrm{Kbp}^{-1}$ and fish host accounted for $51.2 \%$ of the molecular variance.

The isolates from the model river include representatives of the three clonal complexes reported in ayu. The 


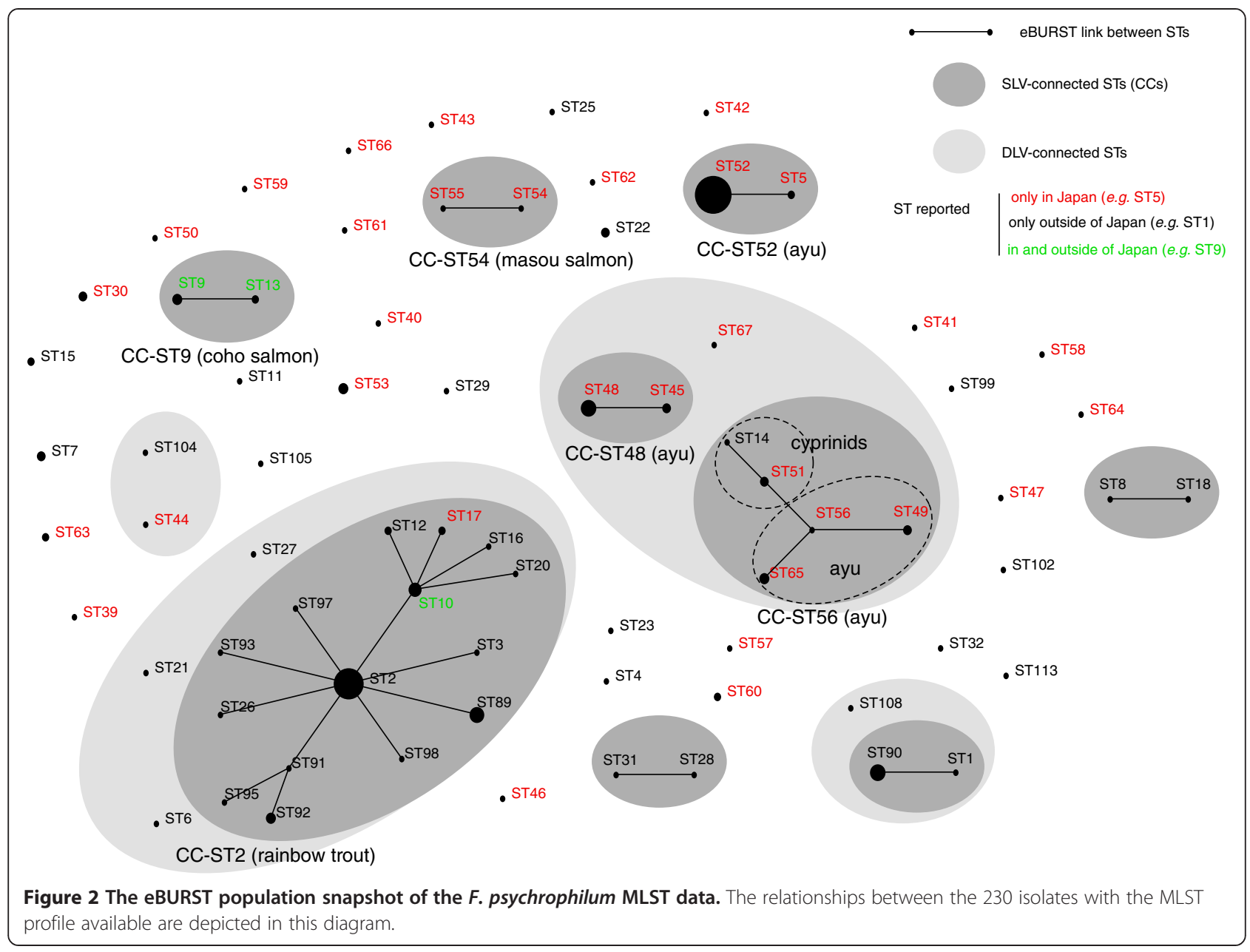

majority of ayu isolates belonged to ST52 and this ST was observed over several seasons (i.e., August 2005, October 2005, April 2006, June 2006, and September 2006). Simultaneously, strains displaying ST52 were also isolated from numachichibu and a water sample suggesting contamination by ayu. A geographical population structure could explain the dominance of CC-ST52 in the model river not seen at the country level. However, at least two other factors may contribute to this difference: a temporal evolution of relative frequencies, since most isolates sampled at the country level were collected years before the sampling of the model river; and the fish sampling strategy, since sampling in the model river was performed irrespectively of disease symptoms and CC-ST52 seems less virulent [14]. Seven ST (ST59, ST60, ST61, ST62, ST63, ST64, and ST66) not connected to those found in ayu were retrieved from river water, a case of caddisfly, and several local fish. These strains were isolated in November 2005, November 2006 and December 2006, when ayu are absent from the river due to their one-year life cycle ending after spawning in the autumn. Six of these strains (no data available on ST66) showed no pathogenicity against ayu [14]. These ST may have gone unnoticed if other fish species and the environment had not been sampled.

Importantly, co-infection of the same individual fish by different lineages was detected four times in ayu (Table 1). This observation could have a practical interest in the context of disease prevention or treatment but could also have important evolutionary implications. In particular, co-infection might promote evolution towards higher virulence [36], in particular if distinct transmission modes -horizontal and vertical- are involved [42]. The local diversity of F. psychrophilum genotypes detected in the model river, which goes down to the level of the individual host fish, also certainly contributes to explain the very high recombination rate detected in the species on the basis of MLST data $[17,43]$. Indeed, a greater local diversity provides more opportunities to exchange alleles and therefore directly increases the apparent recombination rate and the actual genetic mixing. 


\section{Additional files}

Additional file 1: Isolates representative of diversity at the country level. Institutions that provided these isolates and previous publications on these isolates are listed [11,14,16,44-47].

Additional file 2: MLST scheme. PCR and sequencing primers for the seven loci as well as the corresponding experimental protocols are provided.

\section{Abbreviations}

BCWD: Bacterial cold water disease; PCR: Polymerase chain reaction; PBS: Phosphate buffered saline; MLST: Multilocus sequence typing; CC: Clonal complex; ST: Sequence type; AT: Allele type; SLV: Single locus variant; DLV: Double locus variant.

\section{Competing interests}

The authors declare that they have no competing interests.

\section{Authors' contributions}

EFN performed fish sampling in the model river, bacterial isolation, and contributed to sample processing, data analysis and writing of the manuscript. CCD contributed to the development and optimization of the MLST scheme and to sample processing. JFB and ME contributed to data analysis and presentation of the results. ED initiated the project and contributed to data analysis. PN analyzed the data and wrote the manuscript. All authors read and approved the final manuscript.

\section{Acknowledgements}

We are grateful to the organizations listed in Additional file 1 for providing F. psychrophilum strains. We also wish to thank Dr K. Sugahara, J. Ikeda, and A. Fukuda for help with field sampling and technical assistance and Dr Keith Jolley at University of Oxford for hosting the F. psychrophilum MLST database. This work received the support of a Grant-in-Aid for Young Scientists, KAKENHI (B) (18780153) and a Grant-in-Aid from the Global Center of Excellence (COE) Program, Japan. EFN was also supported by Research Fellowships from the Japan Society for the Promotion of Science for Young Scientists and PN, CCD, JFB and ED by ANR (ANR-07-GMGE-004 Flavophylogenomics) and EU EMIDA ERA-NET (ANR 2010-EMID-006-01 Pathofish).

\section{Author details}

${ }^{1}$ Department of Fisheries, Kinki University, Nara, Japan. ${ }^{2}$ INRA, Virologie et Immunologie Moléculaires UR892, Jouy-en-Josas, France. ${ }^{3}$ INRA, Mathématique Informatique et Génome UR1077, Jouy-en-Josas, France.

Received: 28 November 2012 Accepted: 25 April 2013

Published: 17 May 2013

\section{References}

1. Cabello FC: Heavy use of prophylactic antibiotics in aquaculture: a growing problem for human and animal health and for the environment. Environ Microbio/ 2006, 8:1137-1144.

2. Cipriano RC, Holt RA: Flavobacterium psychrophilum, cause of Bacterial Cold-Water Disease and Rainbow Trout Fry Syndrome, Fish Disease Leaflet No 86. Kearneysville, W: US Department of the Interior US Geological Service, National Fish Health Research Laboratory; 2005.

3. Wakabayashi H, Horiuchi M, Bunya T, Hoshiai G: Outbreaks of cold-water disease in Coho salmon in Japan. Fish Pathol 1991, 26:211-212.

4. Bernardet JF, Kerouault B: Phenotypic and genomic studies of "Cytophaga psychrophila" isolated from diseased rainbow trout (Oncorhynchus mykiss) in France. Appl Environ Microbiol 1989, 55:1796-1800.

5. Borg AF: Studies on myxobacteria associated with diseases in salmonid fishes. University of Washington; 1948

6. Wakabayashi H, Toyama T, lida T: A study on serotyping of Cytophaga-psychrophila isolated from fishes in Japan. Fish Pathol 1994, 29:101-104.

7. Kumagai A: Bacterial coldwater disease in coho salmon. Nippon Suisan Gakkaishi 2005, 71:645-649.

8. Izumi S, Aranishi F: Relationship between gyrA mutations and quinolone resistance in Flavobacterium psychrophilum isolates. Appl Environ Microbiol 2004, 70:3968-3972
9. Kumagai A, Yamaoka S, Takahashi K, Fukuda H, Wakabayashi H: Waterborne transmission of Flavobacterium psychrophilum in coho salmon eggs. Fish Pathol 2000, 35:25-28.

10. Ishiguro N, Miya M, Nishida M: Complete mitochondrial DNA sequence of ayu Plecoglossus altivelis. Fish Sci 2001, 67:474-481.

11. Miwa S, Nakayasu C: Pathogenesis of experimentally induced bacterial cold water disease in ayu Plecoglossus altivelis. Dis Aquat Organ 2005, 67:93-104.

12. Lehmann J, Mock D, Stürenberg FJ, Bernardet J-F: First isolation of Cytophaga psychrophila from a systemic disease in eel and cyprinids. Dis Aquat Organ 1991, 10:217-220.

13. Nematollahi A, Decostere A, Pasmans F, Haesebrouck F: Flavobacterium psychrophilum infections in salmonid fish. J Fish Dis 2003, 26:563-574.

14. Fujiwara-Nagata E, Ikeda J, Sugahara K, Eguchi M: A novel genotyping technique for distinguishing between Flavobacterium psychrophilum isolates virulent and avirulent to ayu, Plecoglossus altivelis altivelis (Temminck \& Schlegel). J Fish Dis 2012, 35:471-480.

15. Amita K, Hoshino M, Honma T, Wakabayashi H: An investigation on the distribution of Flavobacterium psychrophilum in the Umikawa River. Fish Pathol 2000, 35:193-197.

16. lida Y, Mizokami A: Outbreaks of coldwater diseases in wild ayu and pale chub. Fish Pathol 1996, 31:157-164.

17. Nicolas P, Mondot S, Achaz G, Bouchenot C, Bernardet J-F, Duchaud E: Population structure of the fish-pathogenic bacterium Flavobacterium psychrophilum. Appl Environ Microbiol 2008, 74:3702-3709.

18. Izumi S, Aranishi F, Wakabayashi H: Genotyping of Flavobacterium psychrophilum using PCR-RFLP analysis. Dis Aquat Organ 2003, 56:207-214.

19. Chakroun C, Grimont F, Urdaci MC, Bernardet J-F: Fingerprinting of Flavobacterium psychrophilum isolates by ribotyping and plasmid profiling. Dis Aquat Organ 1998, 33:167-177.

20. Soule M, LaFrentz S, Cain K, LaPatra S, Call DR: Polymorphisms in 16S rRNA genes of Flavobacterium psychrophilum correlate with elastin hydrolysis and tetracycline resistance. Dis Aquat Organ 2005, 65:209-216.

21. Madsen L, Dalsgaard I: Reproducible methods for experimental infection with Flavobacterium psychrophilum in rainbow trout Oncorhynchus mykiss. Dis Aquat Organ 1999, 36:169-176.

22. Garcia C, Pozet F, Michel C: Standardization of experimental infection with Flavobacterium psychrophilum, the agent of rainbow trout Oncorhynchus mykiss fry syndrome. Dis Aquat Organ 2000, 42:191-197.

23. Decostere A, Lammens M, Haesebrouck F: Difficulties in experimental infection studies with Flavobacterium psychrophilum in rainbow trout (Oncorhynchus mykiss) using immersion, oral and anal challenges. Res Vet Sci 2000, 69:165-169.

24. Ekman E, Akerman G, Balk L, Norrgren L: Nanoinjection as a tool to mimic vertical transmission of Flavobacterium psychrophilum in rainbow trout Oncorhynchus mykiss. Dis Aquat Organ 2003, 55:93-99.

25. Duchaud E, Boussaha M, Loux V, Bernardet J-F, Michel C, Kerouault B, Mondot S, Nicolas P, Bossy R, Caron C, Bessières P, Gibrat JF, Claverol S, Dumetz F, Le Hénaff $M$, Benmansour A: Complete genome sequence of the fish pathogen Flavobacterium psychrophilum. Nat Biotechnol 2007, 25:763-769.

26. Siekoula-Nguedia C, Blanc G, Duchaud E, Calvez S: Genetic diversity of Flavobacterium psychrophilum isolated from rainbow trout in France: predominance of a clonal complex. Vet Microbio/ 2012, 161:169-178.

27. Aoki M, Kondo M, Nakatsuka Y, Kawai K, Oshima SI: Stationary phase culture supernatant containing membrane vesicles induced immunity to rainbow trout Oncorhynchus mykiss fry syndrome. Vaccine 2007, 25:561-569.

28. Izumi S, Wakabayashi H: Sequencing of gyrB and their application in the identification of Flavobacterium psychrophilum by PCR. Fish Pathol 2000, 35:93-94.

29. Toyama T, Kita-Tsukamoto K, Wakabayashi H: Identification of Cytophaga psychrophila by PCR targeted 16s ribosomal RNA. Fish Pathol 1994, 29:271-275.

30. Ewing B, Hillier L, Wendl MC, Green P: Base-calling of automated sequencer traces using phred. I. Accuracy assessment. Genome Res 1998 8:175-185.

31. Maiden MCJ, Bygraves JA, Feil E, Morelli G, Russell JE, Urwin R, Zhang Q, Zhou JJ, Zurth K, Caugant DA, Feavers IM, Achtman M, Spratt BG: Multilocus sequence typing: a portable approach to the identification of clones within populations of pathogenic microorganisms. Proc Natl Acad Sci U S A 1998, 95:3140-3145. 
32. Urwin R, Maiden MCJ: Multi-locus sequence typing: a tool for global epidemiology. Trends Microbiol 2003, 11:479-487.

33. The F. psychrophilum MLST database [http://pubmlst.org/fpsychrophilum/].

34. Jolley KA, Maiden MC: BIGSdb: Scalable analysis of bacterial genome variation at the population level. BMC Bioinformatics 2010, 11:595.

35. Feil EJ, Li BC, Aanensen DM, Hanage WP, Spratt BG: eBURST: Inferring patterns of evolutionary descent among clusters of related bacterial genotypes from multilocus sequence typing data. J Bacteriol 2004, 186:1518-1530.

36. Excoffier L, Smouse PE, Quattro JM: Analysis of molecular variance inferred from metric distances among DNA haplotypes: application to human mitochondrial DNA restriction data. Genetics 1992, 131:479-491.

37. Wright S: Evolution in Mendelian populations. Genetics 1931, 16:97-159.

38. Slatkin M: Rare alleles as indiators of gene flow. Evolution 1985, 39:53-65.

39. Madetoja J, Nystedt S, Wiklund T: Survival and virulence of Flavobacterium psychrophilum in water microcosms. FEMS Microbiol Ecol 2003, 43:217-223.

40. Deleon-Rodriguez N, Lathem TL, Rodriquez RL, Barazesh JM, Anderson BE, Beyersdorf AJ, Ziemba LD, Bergin M, Nenes A, Konstantinidis KT: Microbiome of the upper troposphere: Species composition and prevalence, effects of tropical storms, and atmospheric implications. Proc Natl Acad Sci USA 2013, 110:2575-2580.

41. Cipriano RC: Intraovum infection caused by Flavobacterium psychrophilum among eggs from captive Atlantic salmon broodfish. J Aquat Anim Health 2005, 17:275-283.

42. Nowak MA, May RM: Superinfection and the evolution of parasite virulence. Proc Biol Sci 1994, 255:81-89.

43. Jones EO, White A, Boots M: The evolutionary implications of conflict between parasites with different transmission modes. Evolution 2010, 64:2408-2416

44. Fujiwara-Nagata E, Eguchi M: Development and evaluation of a loopmediated isothermal amplification assay for rapid and simple detection of Flavobacterium psychrophilum. J Fish Dis 2009, 32:873-881.

45. Ryumae U, Hibi K, Yoshiura Y, Ren HF, Endo H: Ultra highly sensitive method for detecting Flavobacterium psychrophilum using high-gradient immunomagnetic separation with a polymerase chain reaction. Aqua Res 2012, 43:929-939.

46. Sugahara K, Fujiwara-Nagata E, Eguchi M: Dynamics of the bacterial cold-water disease pathogen, Flavobacterium psychrophilum, in infected fish organs and rearing water after warmed water treatment. Fish Pathol 2010, 45:58-65.

47. Nagai T, Nakai T: Growth of Flavobacterium psychrophilum in fish serum correlates with pathogenicity. J Fish Dis 2011, 34:303-310.

doi:10.1186/1297-9716-44-34

Cite this article as: Fujiwara-Nagata et al.: Population structure of the fish pathogen Flavobacterium psychrophilum at whole-country and model river levels in Japan. Veterinary Research 2013 44:34

\section{Submit your next manuscript to BioMed Central and take full advantage of:}

- Convenient online submission

- Thorough peer review

- No space constraints or color figure charges

- Immediate publication on acceptance

- Inclusion in PubMed, CAS, Scopus and Google Scholar

- Research which is freely available for redistribution

Submit your manuscript at www.biomedcentral.com/submit
C Biomed Central 